\title{
Compreensões de Professores sobre Abordagens das Biotecnologias no Ensino de Química
}

\section{Teachers' Comprehensions about Approaches of Biotechnologies in Chemistry Teaching}

\author{
Leonardo Victor Marcelino ${ }^{\mathrm{a}}$; Carlos Alberto Marques ${ }^{\mathrm{a}}$ \\ a Departamento de Metodologia de Ensino, Universidade Federal de Santa Catarina, Florianópolis, Brasil - \\ leovmarcelino@gmail.com, carlos.marques@ufsc.br
}

\section{Palavras-chave: \\ Ensino de biotecnologia. Ensino de química. Mato Grosso do Sul. Transgênicos. Soja.}

\section{Keywords:}

Biotechnology teaching. Chemistry teaching. Mato Grosso do Sul. Transgenic Soy.
Resumo: Ao tomar como exemplo o estado do Mato Grosso do Sul, marcado pela produção de soja transgênica, propusemo-nos a questionar quais relações professores de Química do ensino médio campo-grandense estabelecem entre biotecnologias e o ensino de Química. Em uma pesquisa qualitativa que abarcou um estudo de caso comparativo, realizamos entrevistas com um professor de uma escola da zona rural desse estado e dois professores de uma escola urbana de Campo Grande. As falas foram integralmente transcritas e analisadas por meio da análise textual discursiva, revelando que os professores não abordam com profundidade as biotecnologias em suas aulas, devido à complexidade desse conhecimento. A formação de professores e as relações mais aproximativas com as universidades são apontadas como meios de possibilitar a abordagem desse tema de caráter socialmente desafiador e tecnologicamente polêmico.

\begin{abstract}
As we take the federative unity of Mato Grosso do Sul for example, which is marked by the large production of transgenic soy, we intended to research the relations established between biotechnologies and chemistry teaching by high school chemistry teachers from Campo Grande. The qualitative research was a Comparative Study Case-type, relying on interviews with one teacher from a country school and two teachers from a urban school. Their speeches were entirely transcript and analyzed by means of Discursive Textual Analysis, highlighting that teaches do not approach deeply the biotechnologies in their classes, due to the complexity of this knowledge. The teachers training and closer relations with universities are pointed out as means to enable the teaching of this theme which is socially defying and technologically polemical.
\end{abstract}




\section{Considerações iniciais}

Atualmente, definem-se as biotecnologias como o uso de organismos vivos ou suas partes para a produção de bens ou serviços (MALAJOVICH, 2012). Definições mais corriqueiras a(s) coloca $(\mathrm{m})$ como um conjunto de técnicas que envolvem a manipulação de organismos vivos para a obtenção de produtos específicos ou modificação de produtos. Segundo a Convenção sobre Biodiversidade da Organização das Nações Unidas (ONU, 1992, Art. $2^{\circ}$ ), biotecnologia significa "qualquer aplicação tecnológica que utilize sistemas biológicos, organismos vivos, ou seus derivados, para fabricar ou modificar produtos ou processos para utilização específica", de modo que esta envolve um campo de conhecimentos, técnicas e, principalmente, interesses de vários tipos.

Para Gilding e Pickering (2011, p. 4, tradução nossa), esse é "um espaço social onde agentes estão localizados de acordo com seu poder de 'capital' nas diferentes formas". Esses atores interagem com os conhecimentos uns dos outros, sob entendimentos comuns (mais intersubjetivos do que baseados em critérios objetivos), com interesses convergentes, organizados em relações hierárquicas (quem tem poder e quem não tem) e debaixo das regras que os governam. Mas vale notar que se deve falar em biotecnologias (no plural), pois o intuito é de estabelecer as múltiplas práticas e conhecimentos envolvidos no campo biotecnológico, desde a parte de fermentação até a moderna genética (GUERRA et al., 1998). O eventual uso do termo no singular assume uma conotação genérica que perpassa essas diferentes técnicas: a transformação material por meio de sistemas vivos e suas partes.

As ligações entre a Biotecnologia e a Química remetem ao início do sec. XX, com a indústria de transformação de materiais, devido às dificuldades geradas pelas duas grandes guerras mundiais. Com isto, desenvolveram-se processos que utilizavam substratos baratos e acessíveis, usando procedimentos microbiológicos com metabólitos primários (MALAJOVICH, 2012). Esses processos fermentativos foram de extrema importância para a indústria química e um dos pilares da formação da Biotecnologia Industrial, cujo intuito é de substituir a via química tradicional desenvolvendo "processos que possibilitem a produção de produtos, materiais e energia a um custo competitivo e com menor impacto ambiental" (MALAJOVICH, 2012, p. 110). Seu surgimento se dá, principalmente, pela percepção da finitude do petróleo e da necessidade de meios de produção menos impactantes ao meio ambiente. Estima-se que em 2010 de 9 a 20\% das vendas do setor químico derivariam da biotecnologia industrial.

No Brasil, Oswaldo Lima foi químico pioneiro no uso da microbiologia para produzir acetona e ácido butírico na primeira metade do século XX (CARVALHO, 1995). Mas foi a partir de 2003 que se intensificaram o debate e a produção biotecnológica no país com a introdução da soja transgênica que, embora já fosse plantada irregularmente há tempos em 
solo brasileiro, a partir desse ano era conclamada a ser regulamentada pelo governo federal (TRAYNOR et al., 2007). Em 2009 o país já tinha alcançado o título de segundo maior produtor mundial de alimentos transgênicos, com 21,4 milhões de hectares plantados, atrás apenas dos Estados Unidos (BRASIL, 2010). Grande parte dessa produção transgênica é proveniente de estados do Centro-Oeste, como Mato Grosso do Sul, relacionado com o plantio e exportação de soja.

Se por um lado os chamados produtos biotecnológicos estão cada vez mais presentes em nosso dia a dia, seja pela sua presença na cesta alimentar e/ou pelas controvérsias relacionadas à genética humana e animal, de outra parte as diversas pesquisas têm ressaltado que a população em geral não se apropriou dos conceitos básicos para o entendimento das temáticas que as envolvem (CAVANAGH et al., 2005; DARCIN; TÜRKMEN, 2006; HARMS, 2002; PEDRANCINI et al., 2008; PETERSON, 2000; RAMÓN et al., 2008; SORGO; AMBROZIC-DOLINSEK, 2009).

Assim, é importante que a escola tome para si a responsabilidade de educar em biotecnologia, fazendo-o não só como um meio para se estudar as técnicas e conceitos envolvidos, mas possibilitando ao aluno condições para a tomada de decisões e para o debate em assuntos polêmicos que a envolve. Nessa perspectiva, a educação não fica restrita ao mero debate conceitual, pois, se assim fosse, apenas serviria para reforçar tanto a ideia do poder (único) dos saberes do cientista/especialista quanto a neutralidade da ciência. Embora os conceitos, teorias e princípios científicos sejam importantes, a educação deve abranger a discussão dos valores e princípios que norteiam a produção desses conhecimentos e que delimitam o campo de ação humana e consolidam uma estrutura social (SANTOS; MORTIMER, 2002). Participar das decisões é mais do que escolher entre a adoção ou rejeição de um empreendimento científico-tecnológico, como o consumo ou não consumo de transgênicos, por exemplo. Trata-se de participar das decisões dos critérios que regem a agenda científica, que possibilitam a emergência de diversas inovações e que, por conseguinte, definem os investimentos em pesquisas nos transgênicos ou em suas alternativas, a exemplo da agroecologia (AULER, 2002).

Esses pontos evidenciam e reforçam a necessidade de pesquisas que sinalizem e proponham formas de abordar as biotecnologias em escolas de ensino médio, em particular, envolvendo relações entre o ensino de Química e contextos regionais. Estes são os aspectos que se discutem nesta pesquisa, tomando como caso de análise duas escolas sul-matogrossenses, uma delas no meio rural e outra na zona urbana de Campo Grande. Este trabalho, portanto, almeja discutir a abordagem das biotecnologias no ensino de Química, procurando responder ao seguinte questionamento: Quais relações são estabelecidas entre biotecnologias e o ensino de Química por professores de Química do ensino médio? 
Para tanto, organiza-se este texto em cinco seções. Esta introdução, seguida da seção que discute aspectos de ligação entre o ensino de Química com as biotecnologias e o contexto da pesquisa, recolhendo da literatura alguns dos poucos trabalhos que apontam potencialidades e necessidades que essa relação seja explorada. Na terceira seção apresentamse os caminhos de pesquisa. Já na quarta seção, conduz-se a análise sobre as compreensões dos professores entrevistados. Ao fim, apresentam-se as considerações finais como quinta seção.

\section{Biotecnologias e o ensino de Química}

Embora as relações entre a Química e as biotecnologias sejam fortes e crescentes, as biotecnologias não se limitam aos conhecimentos químicos, elas usam conceitos de várias áreas, como a Engenharia Química, Biologia, Biologia Molecular,Bioquímica e outras, o que traz potencialidades para uma perspectiva de ensino que vise superar as conhecidas e criticadas sequências de conteúdos disjuntos e reduzidos (MORIN, 2004) e construir uma explicação única e integrada, configurando-se como um assunto transdisciplinar em potencial. Porquanto, vai além da interdisciplinaridade, pois não se foca em uma disciplina, e também da multidisciplinaridade, pois trata dos eventos com linguagem uniforme de todas as ciências envolvidas (SILVA, 2004). Logo, as biotecnologias são assuntos dos quais podem ser estudados diversos temas, como a bioética no uso de células-tronco e a controvérsia do consumo dos transgênicos. Os temas podem funcionar como articuladores de diversos conteúdos disciplinares, o que parece estar em consonância com uma visão curricular onde se relacionam os conteúdos sistematizados com a realidade dos estudantes de forma transdisciplinar, a exemplo do que é preconizado nos PCN - Parâmetros Curriculares Nacionais (BRASIL, 2000) e também pelo movimento Ciência, Tecnologia e Sociedade (CTS), especialmente via o Pensamento Latino-Americano em Ciência-Tecnologia-Sociedade (PLACTS) (ROSO; AULER, 2016). Contudo, a redução e compartimentalização do conhecimento, como vistas na divisão das disciplinas em sequências rígidas de conteúdos nos referenciais curriculares, podem se configurar como um entrave ao ensino da biotecnologia. Por exemplo, no Referencial Curricular do Ensino Médio de Mato Grosso do Sul (MATO GROSSO DO SUL, 2002) a biotecnologia só é diretamente relacionada no terceiro ano de ensino de biologia, como sequência dos conteúdos de genética.

Apesar de potencialmente enriquecedora na educação, pesquisas sobre a presença do tema da biotecnologia no ensino de Química no Brasil são escassas. Lindemann e colaboradores (2009) relataram a incipiência de investigações sobre esse tema da realidade brasileira. Entretanto, há trabalhos mais atuais que utilizam o tema biotecnológico para o ensino de biologia (KLEIN, 2011) e alguns outros mais antigos que foram voltados para o 
ensino de Química que tratam de transgênicos (PEDRANCINI et al., 2008), fermentação e produção de álcool (FERREIRA; MONTES, 1999; RODRIGUES et al., 2000), biocombustíveis (LINDEMANN et al., 2009) e outros. O que se pode destacar na pesquisa de Lindemann et al. (2009) relativa às concepções de professores de ensino médio sobre biocombustíveis foi a visão dos investigados sobre ciência e tecnologia, que estava direcionada linearmente ao desenvolvimento, contribuindo para uma perspectiva salvacionista científico-tecnológica. Ressaltaram, também, a forte influência da mídia na concepção dos professores sobre biocombustíveis e nas justificativas da inserção do tema no ensino. Os pesquisadores defendem, então, a investigação de concepções de professores sobre determinado tema como um meio de contribuir para as atividades de formação (inicial e continuada), sempre considerando como possibilidades aquilo que o professor já sabe e também os limites de seus conhecimentos. (LINDEMANN et al., 2009). Já Amorim (1998) revela que em um livro didático de biologia o assunto biotecnologia passava a ideia de tecnologia como aplicação da ciência, o que pode resultar, segundo o autor, numa concepção de ciência neutra, sendo a tecnologia a sua aplicação tendenciosa e de supervalorização científica, o cientificismo.

É nesse contexto agrícola e biotecnológico que permeia o Brasil que surgem as inquietações que impulsionam esta pesquisa. Questões sobre o papel da escola na formação de sujeitos que estão em um mundo em relações contraditórias, representando interesses de grupos sociais distintos, precisam ser consideradas no âmbito das escolhas curriculares e das perspectivas de ensino, especialmente o de Ciências/Química. Essas contradições da realidade estão presentes na definição dos objetos de pesquisa da Ciência e Tecnologia (C\&T), como, por exemplo, a escolha em investir em pesquisas sobre transgênicos e não sobre agroecologia (LACEY, 2008). Essas definições da agenda científica se mostram demasiadamente complexas para serem decididas apenas por alguns grupos de pessoas, em determinadas posições de poder. Devem ser submetidas ao debate social amplo, em sentido democrático.

É por isso que Bazzo et al. (2003) defendem a regulação social da ciência e tecnologia, perspectiva que se encontra no centro do movimento CTS, pela crítica à neutralidade científica e defesa de seu sentido de instituição social, que, portanto, é feita e regulada por fatores sociais. Com esse mesmo objetivo, Auler e Delizoicov (2006) aproximam a Alfabetização Científica e Tecnológica Ampliada dos ideais educacionais de Paulo Freire - a educação dialógica-problematizadora. Nessa abordagem educacional, são as situações reais, concretas e significativas que devem ser o ponto de partida e o esquema estruturante do conteúdo programático da escola, buscando a transformação social e participação pública, contribuindo para a regulação social da C\&T (FREIRE, 1975; 2005). 
Roso e Auler (2016) investigaram propostas curriculares no âmbito CTS publicadas em revistas brasileiras do ensino de Ciências, dentre as quais figuram as que corroboram a importância das biotecnologias no ensino de Química, por exemplo. Eles encontram quatro grandes categorias permeando essas produções: I) a construção dos currículos em torno de "temas"; II) foco no cumprimento da matriz curricular historicamente dada; III) ausência de investigação temática; IV) trabalho em focos de cooperação. O alerta dos autores sobre a abordagem temática é que ela não seja reduzida a uma discussão meramente conceitual, sem levar em conta os aspectos sociais e históricos que condicionam a existência de um determinado produto científico e/ou tecnológico, pois pode desconstruir as condições para a dialogicidade, posição que se corrobora nesse trabalho. A focalização em conceitos científicos conduz à prevalência de temas que possibilitem/busquem apenas o cumprimento dos itens da matriz curricular, sem questionar a sua relevância para o atual momento histórico, reduzindo o movimento CTS a uma metodologia de ensino e não na busca de uma reestruturação curricular que questione $o$ que ensinar e por que ensinar. Nesse sentido, a investigação temática, conceito de Paulo Freire (1975; 2005), pode auxiliar a pensar esses questionamentos, explicitando os objetivos educacionais, ainda que esses autores não tenham encontrado trabalhos que focalizam a importância da definição dos temas nos moldes da investigação temática, mas surgiram trabalhos cujo foco das disciplinas era a leitura da realidade em base a uma colaboração entre os professores (ROSO; AULER, 2016).

\section{Caminhos percorridos na pesquisa}

Esta pesquisa foi de caráter qualitativo e exploratório (ESTEBAN, 2012), com a análise de entrevistas semiestruturadas com três professores de Química do ensino médio, da rede pública estadual de Campo Grande (MS). Para entender as compreensões desses professores, dentro de uma realidade em que se acham inseridos, foram escolhidas duas escolas públicas, especialmente pelos contextos que representam: o rural e o urbano. Por esses motivos optou-se por uma "estratégia de projeto de pesquisa" como um estudo coletivo de casos (ESTEBAN, 2012, p. 183) ou estudo de casos múltiplos (YIN, 2001).

A primeira escola tem localização central na cidade de Campo Grande e é administrada pelo governo estadual, ofertando o nível médio e também o segundo ciclo da educação fundamental. É uma das mais antigas e a maior escola em número de matrículas na cidade, com 1.695 matriculados no ensino médio regular (INEP, 2012). Ela recebe alunos provenientes de vários bairros, o que lhe garante estudantes de contextos geográficos e sociais múltiplos. Entretanto, é muito marcada pela realidade urbana e em seus vários elementos: comércio, tecnologias de comunicação, transporte urbano, moradia, poluição (visual, sonora, atmosférica, etc.), entre outros. A escola possui salas de informática, laboratório de ciências, 
biblioteca, sala de leitura e quadra coberta e também curso de logística, pela educação profissional (INEP, 2012). Embora houvesse mais professores de Química atuantes na escola, apenas dois aceitaram participaram da pesquisa.

A outra instituição escolhida foi uma escola agrícola, onde se entrevistou um professor de Química atuante em todas as séries do ensino médio. A partir de 2006, implantou-se na escola o ensino médio integrado à educação profissional com habilitação para agronomia e pecuária, devido ao anseio da população rural atendida pelo prosseguimento dos estudos. Entretanto, os anos iniciais ( $1^{\circ}$ ao $5^{\circ}$ ano) também contam com ensino diferenciado, integral e voltado às atividades desenvolvidas no campo, com foco para o turismo rural. A escola também conta com cozinha experimental, lago de piscicultura, sete bovinos para atividades didáticas, laboratório de ciências, laboratório de informática, biblioteca e quadra coberta (INEP, 2012).

O instrumento de coleta de dados foi a entrevista semiestruturada, gravada em áudio e integralmente transcrita. Forneceu-se aos professores um texto chamado "Falas de Cientistas sobre o Tema Biotecnologias”, produzido por nós para esta pesquisa e que reúne excertos de textos científicos e materiais de divulgação científica que apresentam posições contraditórias sobre os riscos e aceitação dos processos biotecnológicos. Esse texto foi lido antes das perguntas com intuito de fornecer informações básicas para os professores sobre os aspectos das biotecnologias que estavam sendo considerados na pesquisa, visto ser um assunto amplo.

Depois de integralmente transcritas as falas dos professores, o corpus, iniciou-se o processo de análise textual discursiva (ATD) (MORAES; GALIAZZI, 2011). A primeira etapa desse processo é a leitura e significação, em que, a partir do processo de leitura, são focalizadas as unidades que constituem os textos, ou seja, as unidades de significado ou sentido que possibilitam a construção de categorias. Nessa etapa, as falas foram identificadas pelo código da pessoa que as proferiu (PR1: Prof. Rural 1; PU1: Prof. Urbano 1; PU2: Prof. Urbano 2; e ENT: Entrevistador) e pelo turno de fala dentro da entrevista. A essa unidade foram atribuídas palavras-chave, ou termos mais representativos, como aconselham Moraes e Galiazzi (2011), e também associada uma categoria prévia. As categorias podem ser definidas a priori, ou seja, com base nos referenciais teóricos e demais configurações da pesquisa, de forma consciente e planejada; bem como podem surgir de uma auto-organização das unidades de sentido, com base em conhecimentos tácitos do pesquisador, de seus referenciais, de forma inconsciente (MORAES; GALIAZZI, 2011).

Tendo em vista esses princípios metodológicos e os objetivos da pesquisa, estabeleceram-se a priori cinco categorias de análise, das quais se analisam duas neste trabalho: Abordagens das biotecnologias no ensino de Química; e Justificativas para a abordagem das biotecnologias no ensino de Química. 


\section{Compreensões dos professores}

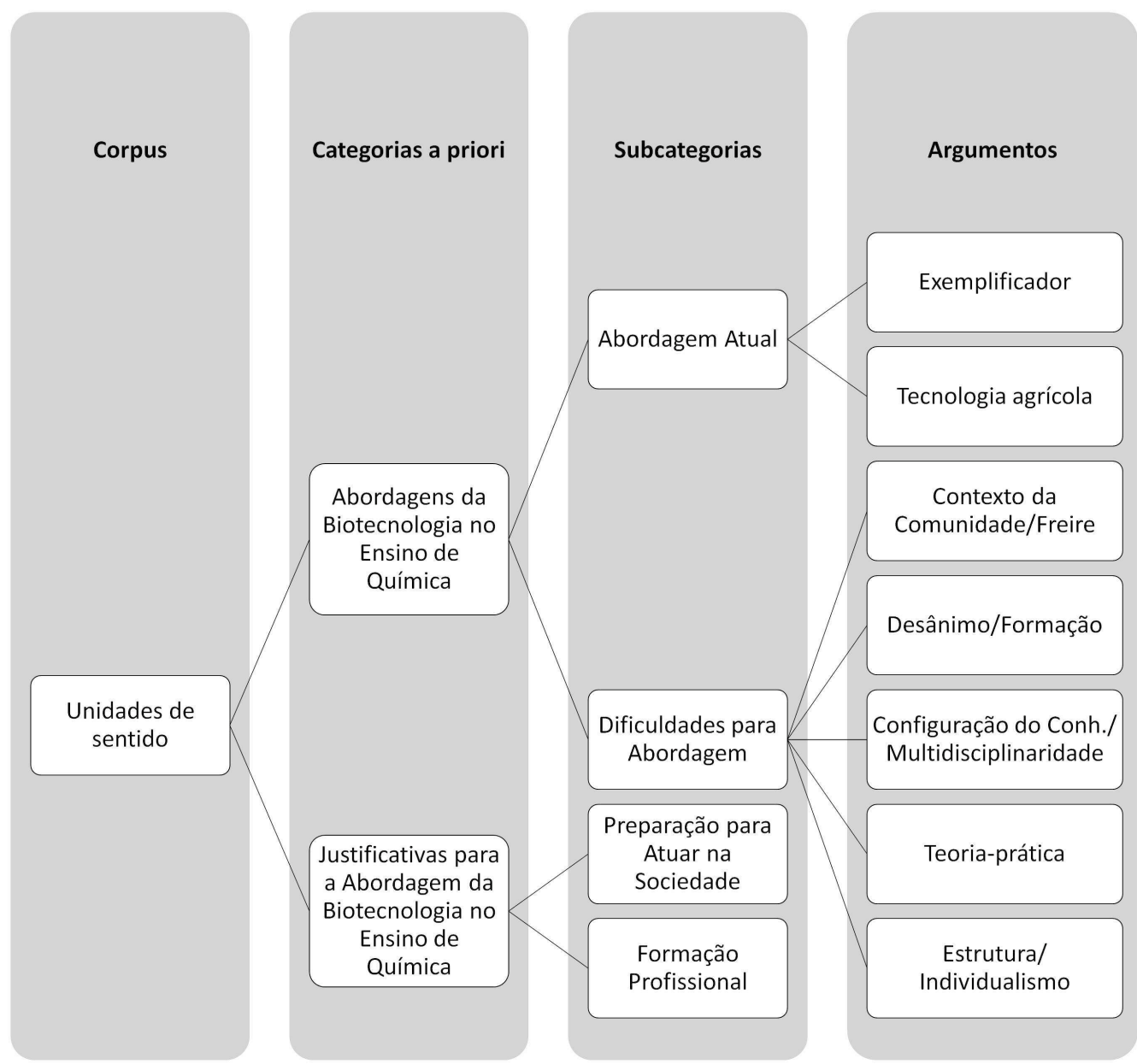

Figura 1- Organização de categorias a priori e subcategorias construídas a partir das entrevistas com professores sobre suas compreensões de biotecnologia.

Fonte: os Autores.

Seguindo os procedimentos da ATD, foi construído um metatexto das análises realizadas, aliando descrição e interpretação das unidades de sentido. O mesmo é a seguir apresentado na forma das categorias que emergiram da análise, cuja estrutura é esquematizada na Figura 1.

\section{Abordagens das biotecnologias no ensino de Química}

Nessa categoria são discutidas as possíveis e já consolidadas abordagens das biotecnologias no ensino da Química, enfatizando algumas dificuldades para sua implantação, com base na compreensão dos professores entrevistados.

Primeiramente, discute-se como as biotecnologias vêm sendo atualmente trabalhadas por estes professores, o que constituiu a subcategoria Abordagem atual. Em seguida, analisam-se obstáculos para essa inclusão, na subcategoria Dificuldades para abordagem, que emerge quando se analisam as dificuldades relatadas pelos entrevistados e que, em alguma medida, apontam para possíveis superações desses obstáculos. 


\section{Abordagem atual}

No geral os professores concordam que não há articulação das biotecnologias com a Química em suas aulas. No entanto, ressaltam momentos em que as biotecnologias aparecem, principalmente como um modo de exemplificar um conceito científico da Química. Na escola urbana, a Abordagem Atual das biotecnologias na Química está vinculada com a exemplificação de conceitos por meio da fermentação e a produção de açúcar e álcool, que fazem parte do contexto regional e vinculada a uma política nacional para o fortalecimento do álcool como combustível. Mas os professores urbanos consideram que essa abordagem é insuficiente, chegando até mesmo a declarar que não chega a haver articulação das biotecnologias com o ensino de Química em si:

PU2-40: [...] Aqui no estado, é um estado que trabalha bastante com agropecuária e tem que falar mais sobre isso. Eu quase não falo. [...]. PU2-44: [...] Na verdade fica muito preso ao conteúdo em si, [...]. Biotecnologia é um tema multidisciplinar, ele não fica só numa área. Acho que é por isso que o professor quase não estuda essa área. $[\ldots]$ (grifo nosso)

Já na escola agrícola, as biotecnologias estão especialmente vinculadas à prática do técnico agrícola. Elas são citadas como exemplo de práticas de cultivo que infringem menor dano ambiental, no que tange ao menor uso de agrotóxicos e ao melhor aproveitamento da área de plantio, impedindo novos desmatamentos. Mesmo assim, não estão vinculadas à disciplina de Química, mas às disciplinas práticas de agronomia e de pecuária, configurandose como uma tecnologia agropecuária. Entretanto, nas componentes regulares está diretamente envolvida com a biologia.

PR1-47: Em determinados momentos, sim. Especificamente nós vamos, a gente acaba falando um pouco na Química Ambiental, acaba entrando em poluição, acaba entrando em exploração, acaba entrando também um pouco em transgênico. Onde, especificamente, é voltado a área de biologia.

Essa abordagem das biotecnologias como exemplificação de conceitos científicos disciplinares parece decorrer ou ter alguma relação com a compreensão das biotecnologias como um campo de práticas baseados em conceitos científicos, como os da Química. A vinculação das biotecnologias com atividades práticas e como modo de exemplificar a aplicação de conhecimentos foi notada também em um livro didático analisado. Nos livros de Feltre (2004a; 2004b) as biotecnologias são associadas com processos produtivos ou acontecimentos cotidianos, mas não são fontes de problematização. Servem apenas para exemplificação dos conceitos estudados. Nota-se, então, uma sintonia entre a abordagem das biotecnologias no livro didático e as compreensões dos professores pesquisados (MARCELINO, 2014).

Convém investigar, portanto, quais as razões para esse aparente afastamento das biotecnologias e da Química, o que se faz a seguir. Sobre isto, os professores citaram diversos 
condicionantes de sua prática, mas também deixaram transparecer possibilidades para a superação desses obstáculos.

\section{Dificuldades para abordagem}

Os professores concordam que seja necessário maior articulação das biotecnologias no ensino de Química, mas elencam uma série de dificuldades para sua concretização, que podem ser resumidas em cinco pontos: 1) o contexto da comunidade e da escola; 2) o desânimo do professor e a falta de conhecimento sobre o tema; 3) a configuração do conhecimento biotecnológico; 4) relação teoria e prática e; 5) as estruturas escolares. Mas, nas falas dos professores sobre essas dificuldades também foram percebidas possibilidades de superação. Essas contradições são exploradas nas seções abaixo.

\section{Contexto da comunidade e da escola}

Os professores elencam dificuldades que se relacionam com as configurações sociais das comunidades em que os alunos convivem, que são interpretadas como fenômenos sociais que entram em choque com o sistema escolar e educacional. O professor PR1 ressalta a evasão e a migração dos alunos pela dinamicidade da vida dos trabalhadores do campo como um fator de dificuldade para o estabelecimento de uma sequência didática consistente e para a continuidade da turma. Ele vislumbra a possibilidade de superação desse problema pela aceitação de alunos da zona urbana, entretanto vê o distanciamento dos alunos da cidade dos meios de produção rural como um entrave, sendo necessária uma organização de estrutura curricular que considere a migração dos alunos, mas que também responda aos conhecimentos vicários da população atendida.

Contudo, os professores das zonas urbana e rural notam que considerar o contexto da comunidade em sala de aula é importante, como uma maneira de dar sentido ao que se aprende. $\mathrm{O}$ contexto está voltado às situações cotidianas que circundam a sociedade e não necessariamente relacionadas à biotecnologia. Com relação a esse assunto, PR1 e PU2 ressaltam as usinas de fermentação, uma atividade biotecnológica, e a produção agropecuária, na qual pode estar inserida a produção de alimentos provenientes de organismos geneticamente modificados (OGMs).

PR1-7: Quando eu falo, por exemplo, fermentação na escola particular [urbana], eles vão se lembrar do quê? Eu tenho que usar coisas que eles vêm em casa. E quando muito, nem vêm. Se falar: alguém aqui já viu alguém fazer pão? Eles vão falar "Não, só vejo ele pronto na padaria." (grifo nosso).

PU2-40: Aqui no estado, é um estado que trabalha bastante com agropecuária e tem que falar mais sobre isso (grifo nosso).

Embora a discussão sobre riscos dos transgênicos tenha sido feita e suscitado o interesse dos professores, eles não explicitaram a importância da produção transgênica para o estado de MS. Os OGMs surgiram das "Falas de Cientistas sobre o Tema Biotecnologias", 
que foi usado como texto-base da entrevista, mas não foram relacionados explicitamente ao contexto regional pelos professores. Assim, parece que esse aspecto do contexto ainda não lhes é claro e precisa, portanto, ser "desvelado".

\section{Desânimo do professor e falta de conhecimento}

A existência do desânimo da parte dos professores parece ter gênese diversa, conforme sua própria fala: a jornada extensa de trabalho, com muitas turmas, com muitos alunos, pouco tempo para planejamento e descanso; a organização escolar, que não promove um ambiente propício a mudanças; a desvalorização profissional do docente, por meio de baixos salários; o desinteresse do aluno nas aulas; conteúdos não significativos; e em certa medida, também a sua pouca familiaridade com os conceitos de determinados assuntos.

PU2-108: Porque, às vezes que eu quis trabalhar um assunto, que eu falei "vou trabalhar", eu fiquei extremamente entusiasmada, mas ao mesmo tempo cansada. Demoraram dias e dias e eu tive que abrir mão de outras coisas. [...] Mas não é impossível, não. Dá para fazer. [...] PU2-150: [...] Só que depende muito do ambiente, né? [...] A escola também não faz nada pra ajudar, aí você "quer saber? Larga mão. Vou continuar a dar minhas aulinhas aí meia boca e está bom." Junta tudo, tudo. Professor desanima muito fácil.

Embora esse tipo de desânimo seja ocasionado por diversos fatores, os professores não o veem como algo intransponível. Segundo eles, uma das alternativas para motivar o professor está em bons cursos de "capacitação" (PU2, sic), que possibilitam repensar a prática, analisá-la sob novos pontos de vista, bem como obter conhecimentos sobre novos temas, novas abordagens. Ponto de vista que corroboramos, pois é fundamental que na formação permanente se insiram as biotecnologias na preparação para o ensino de Química. Nesse sentido, é importante lembrar que a formação contribui tanto para a motivação quanto para a obtenção de conhecimentos.

PU2-162: Se ele não for atrás... Na graduação não vem, vem o que a graduação pode fornecer para a pessoa. Ela não forma totalmente a pessoa. [...] Se é um professor que está desanimado, a escola não ajuda, aí ele vai precisar de força externa. Aí que vai precisar de quem chegue na escola e dá aquele entusiasmo aquele... [...] Aí que entra o curso, né, de capacitação que vai fazer ele se animar, fazer ele ter uma luz, "ah não, eu vou fazer, é mesmo, eu poderia fazer isso". [...] PU2-184: [...] Mas eu acredito que na maioria das vezes é por causa de um motivo, que é mais do que a falta de ousadia, que é a falta de conhecimento. Isso bate com a formação de professores. A falta de conhecimento, a falta de visão global das coisas, de olhar o que está do lado (grifo nosso).

O professor PU2 defende ainda a ousadia para romper com a rotina escolar. Ele fala do impulso inicial que o professor precisa para rever sua prática, modificar sua ação. Embora seja importante como momento inicial, de impulso, a ousadia não pode continuar como um movimento solitário, individualista, em que o professor tome para si toda a responsabilidade pelo sucesso ou fracasso de uma empreitada. A ação dos professores é modulada coletivamente pelas condições concretas da realidade, de forma sistêmica, sendo necessário transformar esses condicionantes para dar espaço à ação individual, o que só é possibilitado 
por um movimento conjunto que desvele essa situação e construa um inédito-viável. Mas o foco na ação individual para resolução de problemas escolares foi encontrado em outras pesquisas (AULER, 2002; COELHO, 2005), revelando um problema comum a ser trabalhado na área de ensino de ciências.

Para PR1 e PU2, as instituições de ensino superior podem contribuir de forma mais ampla com a formação de professores. Eles defendem uma maior relação entre a universidade e as escolas, principalmente para desenvolverem pesquisas em conjunto. Essas relações diferenciadas, segundo os professores, permitem fugir da monotonia da organização curricular e inserir a escola no processo de produção científica.

PR1-97: [...] Então ele tem que estar em contato o tempo todo com a universidade, com mestrado, com doutorado, com alguma coisa. Por quê? Porque ou ele ensina, que é um processo desgastante, um processo muito intensivo, muita atividade em cima disso. Então a gente sente essa falta de pesquisa. E o cara fala assim para ti fechar a boca "te dou duas horinhas de planejamento e está bom". Com duas horas, como se uma pesquisa fosse realizada em duas horas. Nem mesmo um planejamento é realizado nesse tempo, quem dirá uma pesquisa.

Tanto PR1 como PU2, dos contextos rural e urbano respectivamente, reconhecem a necessidade de um contato maior com instituições formadoras. O primeiro por meio das pesquisas, o segundo por meio de ensino e extensão (da formação continuada). Essas instituições, escola e universidade, precisam se aproximar para agir efetivamente na transformação da educação, tanto por meio de cursos de formação, tanto por pesquisas conjuntas. Contudo, é importante salientar, que não tomem apenas os problemas da universidade, mas que se procure responder às indagações da comunidade e da escola.

\section{Configuração do conhecimento biotecnológico}

Uma das afirmações dos professores é a dificuldade de abordagem dos temas das biotecnologias devido a sua complexidade, os quais exigem conhecimentos para além do conhecimento químico, mas também, por exemplo, de muitas correlações socioeconômicas.

PU2-50: Porque é difícil ligar só pra parte de Química, porque você vai acabar voltando, por exemplo, pras questões sociais, as questões econômicas. [...] Mas não tem como ficar só preso na Química, porque ele exige que você tenha outros conhecimentos. Não tem como o professor achar que vai dar aula só de Química em cima de biotecnologia. (grifo nosso).

PR1-49: Porque a área de biologia... é uma parte da biologia. Quando entra na questão de genética, o professor aborda isso aí. Então a gente acaba trabalhando em conjunto. [...] A gente acaba introduzindo isso tanto em Química quanto em biologia, mas ela é mais amplamente aplicada em biologia, essa parte da discussão dos transgênicos (grifo nosso).

Pode-se perceber a dificuldade que encontram para abordar esse tema, que traz ramificações amplas e calcadas fortemente na biologia, mas também no social. É com base na superação destas dificuldades que os professores vislumbram a necessidade de uma ação pedagógica multi ou interdisciplinar, ou seja, que trabalhe o tema biotecnológico na perspectiva de diversas disciplinas escolares. Essa consideração dos professores trouxe um 
ponto de reflexão importante sobre esta pesquisa, que tem seu foco na discussão das biotecnologias, mais especificamente no ensino de Química. Todavia, o intuito deste trabalho não é reduzir a inserção da biotecnologia no ensino de Química, mas de promover a abordagem dentro da Química como disciplina escolar.

Tanto a abordagem das biotecnologias de forma a ultrapassar a disciplinaridade quanto o reconhecimento de sua complexidade estão presentes em discussões em periódicos na área de ensino de ciências (cf. MARCELINO, 2014). A dificuldade em lidar com esses problemas, no entanto, é pouco explorada. Não obstante, o Referencial Curricular de Mato Grosso do Sul (2002) e o livro didático adotado amplamente no estado (MARCELINO, 2014) não trazem de modo explícito as biotecnologias dentro do ensino da Química. No livro se relega o tema à exemplificação de conceitos químicos, enquanto que no Referencial Curricular as biotecnologias só aparecem no rol de conceitos da biologia.

Relação teoria e prática

Os professores da escola urbana relacionam esses dois âmbitos, teoria e prática, pela experimentação e trouxeram à tona a dificuldade de se realizar experimentos, tanto pela complexidade do tema biotecnológico, como pela falta de laboratório, equipamentos e reagentes nas escolas (aspecto a ser discutido na categoria subsequente). Por ora, atém-se à importância dos experimentos contida na fala dos professores:

\footnotetext{
PU1-42: Eu acho que a principal dificuldade é a estrutura da escola, né. O tempo que a gente tem para planejar, para... Para montar um projeto e espaço físico, também. Não tem espaço físico para isso. Enfim, para fazer experimento.

PU2-82: Porque, no caso da fermentação seria mais fácil você até fazer uma aula prática, demonstrativa ou não. Porque, os outros, pra fazer uma aula prática, você trabalharia o tema, discutiria tudo sobre fermentação. Depois até dava pra fazer uma aulinha prática, demonstrativa ou não, pra fechar o assunto.
}

O discurso da experimentação apareceu naturalmente na fala do professor urbano, possivelmente porque eles a veem como um aspecto importante para considerar a abordagem de um conteúdo em sala. Interessante notar na fala de PU2 uma concepção de experimentação bem difundida, baseada num viés positivista, em que a prática seria a comprovação de uma teoria geral. Giordan (1999) faz críticas à essa compreensão do experimento, alertando para o papel do erro e do inesperado durante as experimentações, portanto, indo além da comprovação, para a construção de conceitos.

No fragmento abaixo, também se percebe que há uma pressão administrativa por aulas diferenciadas. Assim, embora PU2 reconheça a importância da experimentação, ele também reconhece que não é qualquer tipo de experimento, que essa é uma ação que exige planejamento e apoio da escola como um todo:

PU2-138: [Acredita-se] que fazer o experimento, o professor que faz experimento é o melhor professor do mundo. Elas acreditam, mas elas não veem, por exemplo, que depende da porcaria daquele experimento. [...] Mas, de que maneira? Se nem 
a escola dá espaço pra você fazer. Por isso que é só ao professor que cabe, ele ser ousado.

Já para o professor PR1, a relação teoria e prática é algo consolidado na escola agrícola, entretanto, em sua fala não aparece menção à experimentação, em qualquer disciplina.

PR1-19: Então, na Química você começa a trabalhar todos os conceitos, ali, de produtos químicos, fertilizantes, o que significa cada um deles [...]. Mas na hora que chega na função sal, eles veem todos os macro nutrientes, todos os micronutrientes. Ali eles já sabem me informar qual é a aplicação de cada um deles: para que eu estou usando potássio na planta, para que eu estou usando nitrogênio, para que eu estou usando fósforo.

Nota-se que em todo percurso escolar rural o aluno está envolvido com atividades práticas. A formação profissional, objetivo da escola, faz parte da seleção dos conteúdos da matriz curricular e é base para dar sentido ao aprendizado conceitual. A prática está, de certa forma, associada à discussão dos conceitos, ainda que no sentido de exemplificação. Trata-se de uma dimensão que é facilitada talvez pela localização da escola, pois ela lida e se situa num contexto bem definido, tendo ainda um objetivo bem consolidado (a formação profissional agronômica e pecuarista). Para a escola urbana, a questão é mais complexa, pois o contexto socioambiental é difuso, formado por alunos provenientes de diferentes bairros da cidade, com condições de infraestrutura diversas. Identificar temas relativos à maioria, senão totalidade, dos alunos exige um esforço pedagógico de investigação dessas realidades, de criatividade na gestão escolar e de interdisciplinaridade.

\section{Estruturas organizacionais escolares}

O papel das estruturas organizacionais escolares também é enfatizado nas falas dos professores, que apontam dificuldades relacionadas às condições físicas e materiais disponibilizadas, bem como aos arranjos sociopolíticos que condicionam as suas ações. Um dos principais pontos que os professores relatam é a falta de laboratórios, ou a sua situação precária.

PU2-140: E eu queria usar um... não tinha uma sala pra usar. Eu estava fazendo oficina na quadra da escola e é ruim. Tem que carregar o material até lá, voltar.

PU1-42: Eu acho que a principal dificuldade é a estrutura da escola, né. O tempo que a gente tem para planejar, para... Para montar um projeto e espaço físico, também. Não tem espaço físico para isso. Enfim, para fazer experimento, para... [...] PU1-52: Então, se a gente for trabalhar só na parte teórica, é... Até dá no colégio, mas se a gente for fazer alguma coisa prática, aí já não dá.

A falta de tempo para trabalhar os conteúdos nas aulas de Química é uma dificuldade maior para os professores da escola urbana, que relatam a necessidade de cumprir a matriz curricular, sendo que o pouco tempo também cria obstáculos para abordar demais assuntos (a exemplo das biotecnologias):

PU1-32: É que na verdade a gente tem um currículo, né, uma grade curricular [sic] para seguir. E aí muitas vezes não dá para você ficar... Não dá para... Isso daqui 
não está incluso na grade, né, então não dá. Nosso tempo é curto, a gente tem duas aulas por semana em cada sala, então não dá tempo (grifo nosso).

PU2-118: Tem que cumprir o conteúdo e às vezes, você fica com número de aulas muito pouco, né. E você não consegue, você tem pouco tempo pra cumprir todo aquele assunto e você não consegue achar um espaço ali pra encaixar uma... Como que chama, quando você... foge.

A falta de espaços adequados para a experimentação, de tempo de planejamento e o excesso de conteúdos a serem trabalhados são problemas que dificultam a abordagem das biotecnologias, consideradas complexas e interdisciplinares. A superação dessas condições envolve mudanças e ações sistêmicas, muito mais do que adaptação às situações esporádicas. Não se trata somente de desenvolver práticas que possam ser realizadas em sala de aula (embora isso também seja extremamente importante), mas trata-se de buscar conjuntamente a transformação da realidade social, nesse caso, pelo envolvimento dos professores e da comunidade na reconstrução dos processos de gestão escolar, seus conteúdos e suas práticas. Nesse sentido, há que se considerar que as estruturas escolares refletem, em certo grau, orientações principalmente externas daquilo que se acha importante estudar e a forma como se as devem estudar.

Nesse sentido, Coelho (2005) ressalta a postura de desesperança dos professores que analisa frente à possibilidade de abordagens temáticas no ensino de Química, devido às barreiras operacionais, que também têm a ver com a infraestrutura escolar. No entanto, ela ressalta a necessária esperança, que se manifesta no desvelamento crítico da realidade, no vislumbramento do inédito-viável (FREIRE, 2005) - algo definido que se torna o objetivo da ação de reflexão e transformação. Ou seja, a autora defende (e aqui se compactua) com o abandono de posições fatalistas e com a busca daquilo que pode ser realizado.

O professor da escola rural, PR1, embora reclame do tempo de planejamento, alega ter certa liberdade temporal para abordar o seu rol de conhecimentos químicos:

PR1-79: Na escola agrícola eu tenho total liberdade curricular. [...] Eu tenho essa liberdade de trabalho e eu não preciso correr, eu preciso trabalhar isso, porque o nosso aluno tem que sair de lá formado. [...] eu posso jogar o que faltou para o ano seguinte. (grifo nosso).

Ainda que ele tenha certa liberdade no gerenciamento do tempo, PR1 não parece ter essa mesma disponibilidade, ou não se atentou para reclamá-la, no que diz respeito à quais conteúdos devam ser abordados. Nesse mesmo sentido, quando questionado sobre o porquê seguir todos os conteúdos já anteriormente determinados no Referencial Curricular do Ensino Médio (MATO GROSSO DO SUL, 2002), PU2 recorre à defesa da responsabilidade do professor em fornecer conhecimentos para que o estudante entenda quimicamente o ambiente ao seu redor, podendo se prevenir dos riscos.

ENT-125: Eu estou lembrando agora, que você também comentou da questão de ficar tão preso ao conteúdo, se era realmente necessário, né. A ideia, do que te obriga ou que te faz seguir tanto essa questão do conteúdo é realmente uma?.... 
PU2-126: O tempo. Responsabilidade, também. Porque, eu acredito... [...] A pessoa tem que ter informação, ela tem que escolher se ela quer comer a uva assim ou não. Ela tem direito, é a responsabilidade (grifo nosso).

Entretanto, o professor também considera necessário romper com essa fixação no cumprimento de conteúdo, por meio da ousadia, a atitude de romper com a estrutura rígida de conhecimentos químicos pré-definidos e abordar aqueles mais significativos para os alunos.

PU2-128: [...] O professor tem que ser ousado, ele tem que desviar um pouco e fazer outra coisa, se não... E ele tem que desviar, porque se ele for seguir só o conteúdo e fazer outras coisas, ou ele vai seguir o conteúdo ou ele não vai. [...] Acham que ele é obrigado a fazer isso, mas não colocam pra ele uma forma dele fazer (grifo nosso).

Mas o professor também ressalta que ele não se sente preparado para transformar sua prática, indicando uma possível falha dos cursos de formação inicial e continuada. Os cursos de formação frequentemente oferecidos são genéricos e desvinculados dos contextos dos professores (CERNY et al., 2014).

Ao explicar quais os conteúdos a serem ensinados, PU2 diz que eles têm a ver com esses conhecimentos necessários para uma atuação (individual) responsável, por meio da escolha entre alternativas disponíveis.

PU2-126: é uma responsabilidade você ter que falar sobre isso que a TV está falando. Ele está indo no mercado, ele está comendo e ele tem direito de escolher ou não se ele quer um produto transgênico, ou, se ele quer só produto orgânico. Feira orgânica tem toda quarta-feira ali na Praça do Rádio. [...] A pessoa tem que ter informação, ela tem que escolher se ela quer comer a uva assim ou não. Ela tem direito, é a responsabilidade.

Todavia, ele parece não reconhecer que essas dificuldades não são (apenas) individuais. Elas são geradas por aspectos determinantes externos muito fortes e por relações estruturais e sociais, tanto no âmbito da decisão, quanto na ação do professor na escola. A presença dos transgênicos no supermercado, por exemplo, é consequência de interesses econômicos de grandes empresas agrícolas, que financiaram as linhas de pesquisa em manipulação genética (LACEY, 2008). Também as dificuldades encontradas em sala de aula refletem as tensões que se estabelecem entre interesses diversos dentro da escola, entre movimentos políticos e demais instâncias superiores. Logo, a transformação não é papel de um indivíduo, mas de uma mobilização das bases dessa estrutura, que de forma conjunta, coletiva, pleiteiem e iniciem tal. Então, a ousadia não pode ficar só no impulso inicial e apenas centrada no indivíduo, muito menos de promover adaptação às condições existentes. A ousadia precisa ter o sentido de questionar as estruturas existentes, de usar a adaptação como meio de iniciar uma educação científica e uma ação que superem essas condições. 


\title{
Justificativas para abordar as biotecnologias no ensino de química
}

No que se refere às compreensões dos professores sobre a importância de se ensinar biotecnologia na disciplina de Química, duas foram as motivações apresentadas em duas subcategorias: Preparação do aluno para atuar em sociedade e Formação profisssional. Convém lembrar que os professores admitem não abordar (PU1 e PU2) ou abordar de forma insatisfatória (PR1) o tema das biotecnologias nas aulas de Química, como destacado na subcategoria Abordagem Atual, acima apresentada. Seguem os argumentos que dão importância pedagógica para a inserção do tema na Química.

\section{Preparação do aluno para atuar em sociedade}

A Preparação do Aluno para Atuar em Sociedade, como uma justificativa para abordar as biotecnologias no ensino de Química, esteve presente nas falas dos professores da escola urbana, vinculando-se à preparação do aluno para atuar na sociedade e para a sua preparação em tomadas de decisão. Parece que esta perspectiva pode estar relacionada ao necessário entendimento das situações quotidianas, daí que se relacione diretamente com a afirmação dos professores da falta de conhecimento sobre o tema que sentem por parte dos alunos. A ideia de ensinar sobre biotecnologia para tomada de decisão surge, por exemplo, em decorrência da constatação de uma controvérsia em relação aos transgênicos (apontada por PU2) e do preconceito envolvendo os transgênicos (apontado por PU1).

\begin{abstract}
PU1-14: É que pelo que eu sei, até hoje só se sabe dos benefícios dos transgênicos, né, que são resistentes à praga e tal. São mais produtivos e tal, só que ainda não se sabe ao certo quais são os malefícios, né. Então é por isso que existe essa, digamos, esse preconceito contra os transgênicos, porque não se sabe ao certo como é que é vai funcionar isso, né (grifo nosso). [...] PU1-28: [...] porque a função do professor é preparar o aluno para a sociedade, né. [...] Na verdade eles têm que decidir se isso é bom ou não, né. Mas a gente tem que direcionar, né.
\end{abstract}

PU2-102: Na vida, mesmo. Porque se ele vai no mercado, essa coisa da alimentação do filho dele e dele. Se ele tá comendo todo dia, se ele está participando da vida aqui fora e ele não sabe o que é um alimento transgênico, não sabe discutir.

A discussão sobre avaliação de riscos no geral é controversa, ainda mais quando se entra em aspectos tão significativos da vida, como saúde e alimentação. Muito embora os professores tivessem acesso ao texto de "Falas de Cientistas sobre o Tema Biotecnologias" com opiniões divergentes, eles ignoraram ou reduziram essa controvérsia, por exemplo, a uma disputa de interesses locais.

PR1-2: Então, o que está acontecendo aí são visões de áreas diferentes. Todas as áreas têm suas competências, mas eu acredito que estaria por traz disso daí uma questão política, econômica: o capitalismo (grifo nosso).

Mesmo assim, os respondentes tiveram problemas em aceitar a controvérsia científica, ignorando-a ou recorrendo a argumentações diversas para atenuá-las, recorrendo aos mitos do salvacionismo e da superioridade científica da tecnologia (AULER, 2002), cujo argumento 
principal está fundado na certeza científica. A certeza científica quanto à segurança dos alimentos transgênicos está relacionada com a suposta existência de testes científicos que a atestam, pelo histórico de consumo que não levou ao surgimento de problemas ambientais e de saúde e, também, pela comprovação dos benefícios obtidos pelas cultivares (variedade cultivada e definida de uma espécie) biotecnológicas, que também já estariam comprovados.

PR1-37: Eu acredito que eu não tenho muito conhecimento para dizer sobre segurança alimentar. Então testes provavelmente já foram feitos. E até o momento não surgiu nenhuma evidência concreta de que alimentos transgênicos pudessem causar uma ou outra interferência na saúde... Então, a gente tem que, como se diz, a gente tem que acreditar, tem que ser a favor, por enquanto.

Por ignorarem as controvérsias por meio da crença nos poderes preditivos da Ciência, os professores recaem num fatalismo, num determinismo tecnológico, em que os transgênicos se tornam uma situação da qual não há superação, um mal necessário. Conforme críticas do movimento CTS (AULER, 2002; DAGNINO, 2008; ROSO e AULER, 2016), a possibilidade de participação cidadã, que se restringia à escolha de produtos já prontos, ignorando processos coletivos de produção de tecnologias e de criação da agenda científica (processos participativamente democráticos), também é minada, pois a decisão é relegada aos cientistas e tecnólogos, pela crença mítica na Ciência. O fatalismo pode ser sinalizado na fala abaixo:

PU1-24: Ah... Ah... Necessário, não sei se seria... ah, necessário [os transgênicos]... Porque não existe outras formas de produzir, né. Isso é evolução, né, da ciência. Acho que ele é mais eficiente, né. (grifo nosso).

\section{Formação profissional}

No contexto agrícola, a justificativa foi fortemente baseada na Formação Profissional. A escola oferece o ensino médio integrado aos cursos técnicos de agronomia e pecuária e as biotecnologias são vistas pelo professor entrevistado como um conhecimento que auxilia na atividade profissional futura, contribuindo para a formação de um profissional diferenciado, mais completo, que tenha os conhecimentos específicos de sua área, mas que possa contribuir e atuar em setores abrangentes.

PR1-53-55: Acredito que seria importante, no caso específico da escola agrícola. Ele é um conteúdo que vai agregar à formação deles, agregar conhecimentos. [...] Então num ponto de vista, eles acabam trabalhando em várias áreas e tendo conhecimento específico, aliás, não específico, tendo um conhecimento tão vasto, assim, eles conseguem atuar nos seus empregos, nas suas áreas de atuação, [...] de uma maneira mais abrangente.

A justificativa da formação profissional se baseia em uma concepção de ensino que pode ter a ascensão econômica do aluno como objetivo, vinculando-a com a superação da situação de pobreza do morador do campo que frequenta a escola. Sem dúvidas esse é um benefício que a educação deve buscar proporcionar. Mas ao mesmo tempo, não se deveria reduzir o ensino e a formação a este objetivo, pois pode se constituir em uma limitação quando se busca questionar e mudar estruturas sociopolíticas, econômicas e ambientais que se 
julguem necessárias. Tal reducionismo recorre fortemente à adaptação social. Do mesmo modo, caso se reduza a educação a esforços individuais, só se reproduz a lógica econômica de performatividade ou, como diria Freire (2005, p. 240), acontece "uma irresistível atração pelo opressor. [...] Na sua alienação querem, a todo custo, parecer com o opressor. Imitá-lo. Seguilo".

É interessante notar que na fala do professor PR1 o objetivo da educação é oferecer oportunidades profissionais para os alunos, mas não necessariamente na fazenda em que o mesmo reside.

PR1-55: Nós temos um aluno lá, que saiu de lá, o que não teve perspectiva nenhuma foi vender, foi ser representante de uma grande empresa de defensivos agrícolas. $\mathrm{O}$ que não teve perspectiva nenhuma; não foi fazer vestibular, não foi fazer nada. Então, o salário dele é um salário bom, pra quem tem aí a idade que ele tem, para quem saiu da família que ele saiu, certo? Então, hoje ele tem... ele mora bem, ele tem... ele vive muito bem [...].

Essa fala encontra ressonância com a educação rural, que esteve voltada à "modernização" do campo pelo emprego de insumos e tecnologias agrícolas, para superar seu suposto caráter de pobre e atrasado. Essa visão preconceituosa do campo contribuiu por fortalecer os latifúndios, detentores do capital para investimento em tecnologias, marginalizando os saberes e práticas dos povos do campo, diminuindo as propriedades familiares, potencializando o êxodo rural (RIBEIRO, 2012). Essa visão tem sofrido crítica de defensores da Educação do Campo, pois a educação rural se encaixa num modelo de produção insustentável, a agricultura convencional, que destrói a produtividade do solo e polui o ambiente. Em contrapartida, a Educação do Campo busca a preservação dos modos de produzir e agir dos camponeses, a manutenção de possibilidades de sua permanência no campo e os saberes tradicionais criados na sua relação com os ecossistemas locais, possibilitando meios de produção integrados ao ambiente - uma abordagem agroecológica (CALDART, 2012; GLIESSMAN, 2000). De forma semelhante, o PLACTS critica a adoção de tecnologias (agrícolas, por exemplo) desvinculadas dos contextos latino-americanos, incorrendo em formas de opressão tecnocrática (DAGNINO, 2008).

Embora os professores não tenham se referido ao CTS, pode-se fazer correlações com esse movimento, amparados por Roso e Auler (2016). O tema das biotecnologias é frequentemente reduzido aos seus conhecimentos científicos disciplinares, seguindo a matriz curricular, o que explicita a contradição entre disciplinaridade e interdisciplinaridade, sendo a forma interdisciplinar requerida, mas vista como impossível pela própria matriz curricular engessada. As biotecnologias ora foram vistas como tecnologia fatalista, sobre a qual não há alternativa, ora como meio necessário para inserção na sociedade capitalista do consumo, revelando posturas desesperançosas (FREIRE, 1975) ou individualistas (AULER, 2002). Essas considerações evidenciam a importância de se pensar criticamente o CTS nas 
reorientações curriculares, repensando as relações entre conhecimento científico, tecnologia e a realidade social latino-americana.

\section{Considerações finais}

A abordagem das biotecnologias no ensino de Química nas escolas de ensino médio analisadas se demonstrou ainda incipiente. Diversos fatores se impõem como dificuldades para a inclusão da biotecnologia no ensino, que podem ser relacionados à estrutura do conhecimento biotecnológico e/ou à questões contextuais, com destaque para os aspectos políticos. As biotecnologias representam um campo de conhecimentos de fronteira, agregando conhecimentos e práticas de diversas áreas, o que representa um problema para um ensino na perspectiva disciplinar, pautado em grades curriculares rígidas e sequenciadas. Não obstante, no tema biotecnológico reside a própria transdisciplinaridade, tão reclamada no ensino de Ciências.

Essa característica potencialmente transdisciplinar da biotecnologia remete à própria complexidade de seu objeto de estudo - a vida - (VICTORINO, 2000), por isso mesmo sendo um tema contextual. Sua vinculação com diversos acontecimentos da vida cotidiana e com disputas de interesses sociais e econômicos são pontos que complexificam a ação docente e o próprio processo de construção do conhecimento e aprendizado. Também a sua amplitude e complexidade entram em choque com as condições de trabalho ofertadas nas escolas. Não é de se estranhar, portanto, a recusa dos professores em participar de uma pesquisa sobre esse tema, fato que levou a uma amostra de pesquisa reduzida. Mas esse embate já mostra alternativas para uma educação que objetive ser transformadora da realidade social. Ao mesmo tempo em que mostra as amarras que impedem a integração do ensino de biotecnologia nas escolas, vislumbram-se as possibilidades de ação e do que pode ser feito.

Entretanto, por meio das justificativas apresentadas pelos professores é possível inferir possibilidades de alinhamento entre os objetivos educacionais das escolas e as abordagens das biotecnologias — já realizadas ou como campo de interesse. A justificativa pela formação profissional embasa o uso das biotecnologias como exemplificação conceitual e técnica no trabalho em disciplinas práticas do curso técnico oferecido na escola agrícola. Também a preparação do aluno para a sociedade é um objetivo que justificaria a abordagem atual na escola urbana que por meio da exemplificação, simulando como os conceitos científicos podem ser úteis para se relacionar com o ambiente, seja por uma postura responsável de prevenção aos riscos, seja para tomada de decisão.

Os professores pensaram em ações individuais de superação dos problemas que dificultam a inserção da biotecnologia no ensino de Química e que dificilmente surtirão efeito para um aprendizado crítico e socialmente comprometido da Química, devido à complexidade 
estrutural da problemática social. Reforça-se, então, a necessidade de cursos de formação inicial e continuada criados pelas universidades e pautados na criação e fortalecimento de grupos de professores que iniciem e mantenham práticas transformadoras dentro da escola, que se ajudem mutuamente e mobilizem mais educadores (comunidade escolar) e a comunidade em que a escola está inserida em torno de um projeto comum.

\section{Referências}

AMORIM, A. C. R. D. Biologia, Tecnologia e Inovação no Currículo do Ensino Médio. Investigações em Ensino de Ciências, v. 3, n. 1, p. 61-80, 1998.

AULER, D. Interações entre Ciência-Tecnologia-Sociedade no contexto da formação de professores de Ciências. Tese de doutorado em Educação - Universidade Federal de Santa Catarina, Florianópolis, 2002.

AULER, D.; DELIZOICOV, D. Educação CTS: Articulação entre pressupostos do educador brasileiro Paulo Freire e referenciais ligados ao movimento CTS. In: Seminario Ibérico CTS en la educación científica, 4., 2006, Málaga-Espanha. Anais... Málaga, 2006. p. 01-09.

BAZZO, W. A.; LINSINGEN, I. V.; PEREIRA, L. T. V. Introdução aos Estudos CTS (Ciência, Tecnologia e Sociedade). Madri: OEI, 2003.

BRASIL. Parâmetros Curriculares Nacionais: bases legais. Brasília: MEC/SEB, 2000.

BRASIL já é $2^{\circ}$ em trangênicos. Gazeta do Povo, 23 de fev. de 2010. Disponível em: < http://www.gazetadopovo.com.br/economia/brasil-ja-e-2-em-transgenicos-e-deve-crescermais-egkx67fkbigj9bqfcz7xgg8jy>. Último acesso em: 31 jan. .

CALDART, R. Educação do Campo. In: CALDART. R. S.; PEREIRA, I. B.; ALENTEJANO, P.; FRIGOTTO, G. (orgs.). Dicionário da Educação do Campo. São Paulo: Expressão Popular, 2012. p. 258-267.

CARVAlHO, H. G. Aspectos da História da Química em Pernambuco de 1935 a 1945. Química Nova, v. 18, n. 3, p. 309-312, 1995.

CAVANAGH, H.; HOOD, J.; WILKINSON, J. Riverina High School students' views of biotechnology. Electronic Journal of Biotechnology, v. 8, n. 2, p. 121-127, 2005.

CERNY, R. Z.; DE ALMEIDA, J. N.; RAMOS, E. Formação continuada de professores para a cultura digital. Revista e-Curriculum,v. 2, n.12, p. 1331-1347, 2014.

COELHO, J. C. A chuva ácida na perspectiva de tema social: um estudo com professores de química de Criciúma. Dissertação de mestrado em Educação Científica e Tecnológica Universidade Federal de Santa Catarina, Florianópolis, 2005.

DAGNINO, R. P. As trajetórias dos estudos sobre ciência, tecnologia e sociedade e da política científica e tecnológica na Ibero-América. Alexandria: Revista de Educação em Ciência e Tecnologia, v. 1, n. 2, p. 3-36, 2008. 
DARCIN, E. S.; TÜRKMEN, L. A study of prospective Turkish science teachers' knowledge at the popular biotechnolical issues. Asia-Pacific Forum on Science Learning and Teaching, v. 7, n. 2, p. 1-13, 2006.

ESTEBAN, M. P. S. Pesquisa Qualitativa em Educação. Porto Alegre: AMGH, 2012.

FELTRE, R. Química: Química Orgânica. São Paulo: Moderna, 2004a. 3 v.

FELTRE, R. Química: Química Geral. São Paulo: Moderna, 2004b. 1 v.

FERREIRA, E.C.; MONTES, R. A química da produção de bebidas alcoólicas. Química Nova na Escola, n. 10, p. 50-51, 1999.

FREIRE, P. Extensão ou Comunicação. Rio de Janeiro: Paz e Terra, 1975.

FREIRE, P. Pedagogia do Oprimido. Rio de Janeiro: Paz e Terra, 2005.

GILDING, M.; PICKERING, J. 'May contain traces of biotech': (re)defining the biotechnology field in Australia. In: The Australian Sociological Association Conference, 16., 2011, Newcastle, Austrália. Anais... New Castle, 2011. Disponível em: < https://www.tasa.org.au/wp-content/uploads/2011/11/Gilding-Pickering-R0129-final.pdf>. Último acesso em: 31 jan. 2017.

GIORDAN, M. O papel da experimentação no ensino de ciências. Química Nova na Escola, n. 10, p. 43-29, 1999.

GLIESSMAN, S.R. Agroecologia: processo ecológicos em agricultura sustentável. Porto Alegre: Ed. Universidade UFRGS, 2000.

GUERRA, M. P.; NODARI, R. O.; REIS, M. S.; SCHMIDT, W. Agriculture, biodiversity, and appropriate biotechnologies in Brazil. Ciência e Cultura, v. 50, p. 408-416, 1998.

HARMS, U. Biotechnology Education in Schools. Electronic Journal of Biotechnology, v. 5, n. 3, p. 1-7, 2002.

INEP. Ministério da Educação. Data Escola Brasil. INEP, 2012. Disponivel em: $<$ http://www.dataescolabrasil.inep.gov.br/dataEscolaBrasil/home.seam>. Acesso em: 31 ago. 2013.

KLEIN, T. A. D. S. Perspectiva Semiótica sobre o Uso de Imagens na Aprendizagem Significativa do Conceito de Biotecnologia por Alunos do Ensino Médio. Tese de doutorado em Ensino de Ciências e Educação Matemática — Universidade Estadual de Londrina, Londrina, 2011.

LACEY, H. Crescimento econômico, meio-ambiente e sustentabilidade social: a responsabilidade dos cientistas e a questão dos transgênicos. In: DUPAS, G. (Org.) Meioambiente e crescimento econômico: tensões estruturais. São Paulo: Editora Unesp, 2008. p. 91-130.

LINDEMANN, R. H.; MUENCHEN, C.; GONÇALVES, F. P.; GEHLEN, S. T.

Biocombustíveis e o ensino de Ciências: compreensões de professores que fazem pesquisa na escola. Revista Electrónica de Enseñanza de las Ciencias, v. 8, n. 1, p. 342-358, 2009. 
MALAJOVICH, M. A. Biotecnologia: Fundamentos. Rio de Janeiro: Biblioteca Max Feffer, 2009. $1 \mathrm{v}$.

MARCELINO, L. V. Compreensões de professores sobre abordagens da biotecnologia no ensino de química. Dissertação de mestrado em Educação Científica e Tecnológica) Universidade Federal de Santa Catarina, Florianópolis, 2014.

MATO GROSSO DO SUL. Referêncial Curricular do Ensino Médio. Campo Grande: SED, 2002.

MORAES, R.; GALIAZZI, M. D. C. Análise Textual Discursiva. Ijuí: Unijuí, 2011.

MORIN, E. Os Setes Saberes Necessários à Educação do Futuro. Brasília: UNESCO, 2004.

ONU. Declaração do Rio sobre Meio Ambiente e Desenvolvimento. Conferência das Nações Unidas sobre Meio Ambiente e Desenvolvimento. Rio de Janeiro, p. 4. 1992.

PEDRANCINI, V. D.; CORAZZA-NUNES, M. J.; GALUCH, M. T. B.; MOREIRA, A. L. O. R; NUNES, W. M. C. Saber científico e conhecimento espontâneo: opiniões de alunos do ensino médio sobre transgênicos. Ciência \& Educação, v. 15, n. 1, p. 135-146, 2008.

PETERSON, R. K. D. Public Perceptions of Agricultural Biotechnology and Pesticides: Recent understandings and implications for risk communication. American Entomologist, v. 46, n. 1, p. 8-16, 2000.

RAMÓN, D.; DIAMANTE, A.; CALVO, M. D. Food Biotechnology and Education. Electronic Journal of Biotechnology, v. 11, n. 5, p. 1-5, 2008.

RIBEIRO, M. Educação Rural. In: CALDART. R. S.; PEREIRA, I. B.; ALENTEJANO, P.; FRIGOTTO, G. (orgs.). Dicionário da Educação do Campo. São Paulo: Expressão Popular, 2012. p. 295-301.

RODRIGUES, J. R.; DE AGUIAR, M. R. M. P.; MARIA, L. C. S.; SANTOS, Z. A. M. Uma Abordagem Alternativa para o Ensino da Função Álcool. Química Nova na Escola, n. 12, p. 20-23, 2000.

ROSO, C. C.; AULER, D. A participação na construção do currículo: práticas educativas vinculadas ao movimento CTS. Ciência \& Educação, v. 22, n. 2, p. 371-389, 2016.

SANTOS, W. L. P.; MORTIMER, E. F. Uma análise de pressupostos teóricos da abordagem C-T-S (Ciência-Tecnologia-Sociedade) no contexto da educação brasileira. Ensaio, v. 2, n. 2 , p. 1-23, 2002.

SILVA, Í. B. Uma pedagogia multidisciplinar, interdisciplinar ou transdisciplinar para o Ensino/Aprendizagem de Física. In: CONGRESSO BRASILEIRO DE EXTENSÃO UNIVERSITÁRIA, 2., Belo Horizonte, 2004. Anais... Belo Horizonte, 2004. Disponível em: http://www.ufmg.br/congrext/Educa/Educa173.pdf. Acesso em 24/02/2010. Último acesso em 13 nov. 2015.

SORGO, A.; AMBROZIC-DOLINSEK, J. The relationship among knowledge of, attitudes toward and acceptance of genetically modified organism (GMOs) among Slovenian teachers. Electronic Journal of Biotechnology, v. 12, n. 3, p. 1-13, 2009. 
TRAYNOR, P. L.; ADONIS, M.; GIL, L. Strategic approaches to informing the public about biotechnology in Latin America. Electronic Journal of Biotechnology, v. 10, n. 2, p. 169-177, 2007.

VICTORINO, V. I. P. A revolução da biotecnologia - questões de sociabilidade. Tempo Social, v. 12, n. 2, p. 129-145, 2000.

YIN, R. K. Estudo de Caso: Planejamento e Métodos. Porto Alegre: Bookman, 2001.

\section{SOBRE OS AUTORES}

LEONARDO VICTOR MARCELINO. Possui graduação em Licenciatura em Química pela Universidade Federal de Mato Grosso do Sul (UFMS, 2011) e mestrado em Educação Cientifica e Tecnológica pela Universidade Federal de Santa Catarina (UFSC, 2014). Atualmente, é aluno de doutorado no Programa de Pós-Graduação em Educação Científica e Tecnológica da UFSC e participa do Grupo de Investigação no ensino de Química (GIEQUFSC).

CARLOS ALBERTO MARQUES. É licenciado, bacharel (1988) e mestre (1991) em Química pela Universidade Federal de Santa Catarina - UFSC. É doutor em Ricerche in Scienze Chimiche pela Universita' degli Studi di Venezia - Itália (1995). Realizou pósdoutorado na Itália (2010) sobre o tema da Química Verde na Educação Química Escolar. É professor Titular da Universidade Federal de Santa Catarina e Coordenador do Programa de Pós-Graduação em Educação Científica e Tecnológica (PPGECT). Bolsista Produtividade em Pesquisa - CNPq. Diretor Geral da Divisão de Ensino da Sociedade Brasileira de Química. Coordena o Grupo de Investigação no ensino de Química (GIEQ-UFSC).

Recebido: 23 de fevereiro de 2016.

Revisado: 29 de novembro de 2016.

Aceito: 24 de janeiro de 2017. 